-

\title{
Key Factors of Successful Corporate Environmental Practice in Selected Malaysia Public Listed Companies
}

\author{
Nur Syuhada Jasni, Haslinda Yusoff \\ Faculty of Accountancy, \\ Universiti Teknologi MARA (UiTM) Selangor, Malaysia \\ nursy168@uitm.edu.my, hasli229@uitm.edu.my: \\ Tel: 03-32587494
}

\begin{abstract}
Today, the issue of corporate environmental practice has been discussed extensively in research and operation because the future of sustainability is at stake. Thus, this paper's objectives are 1) to understand the corporate environmental practice and 2) to determine the key factors of successful corporate environmental practice. Data were gathered from semi-structured interviews with representatives from several prominent Public Listed Companies (PLCs) in Malaysia, which are the pioneer in this area. Findings from this study reveal that companies should have clear environmental guidelines, and most importantly enhanced data governance for greater corporate environmental practice. The conclusion discusses the continuous improvement in navigating and planning future research.
\end{abstract}

Keywords: Corporate environmental practics; Operationalisation, Data governance; Resilience

eISSN: 2398-4287@ 2020. The Authors. Published for AMER ABRA cE-Bs by e-International Publishing House, Ltd., UK. This is an open access article under the CC BYNC-ND license (http://creativecommons.org/licenses/by-nc-nd/4.0/). Peer-review under responsibility of AMER (Association of Malaysian Environment-Behaviour Researchers), ABRA (Association of Behavioural Researchers on Asians) and cE-Bs (Centre for Environment-Behaviour Studies), Faculty of Architecture, Planning \& Surveying, Universiti Teknologi MARA, Malaysia.

DOI: https://doi.org/10.21834/ebpj.v5i15.2421.

\subsection{Introduction}

Currently, companies are more focused on 'doing good to look good', which looks like branding on the surface; thus, many have debated its real impact. Meanwhile, the primary focus of generating profit at the expense of human health and welfare is intolerable as the irresponsible actions will put the future of sustainability at stake. The lesson learned from the financial crisis of 2008-2010 was that irresponsible governance and unethical operation of companies had generated severe costs, which was incurred not only by direct shareholders but also caused a significant systemic burden for communities and the general public (Aluchna \& Idowu, 2017). Furthermore, the situation was a 'lose-lose' situation, whereby companies ended-up facing negative financial consequences (i.e., lawsuits, cost of destruction, etc.) due to poor governance.

Meanwhile, many previous studies examining corporate environmental practice focused on the motivation for companies to include environmental practices in their business operation. The argument may be partly due to the dominant focus on environmental reporting practices instead of corporate practices in the literature (Mohd Zawawi \& Abd Wahab, 2019). Indeed, companies reassured that they are legitimate by taking necessary environmental actions to close the gap that rose due to Industrial Revolution (IR) being a significant cause of sustainability destruction. However, there is unclear evidence showing the ways companies responded to corporate environmental practice to have better company performance (Aagaard, 2018). Consequently, the success of environmental incorporation practice depends on how companies implemented such practice into their business.

The business strategy is vital in engaging corporate environmental practice to lower operating costs and emissions, enhance the reputation, obtain approval for operating license and boost stakeholder engagement. Besides, drivers, strategies and performance

eISSN: 2398-4287@ 2020. The Authors. Published for AMER ABRA cE-Bs by e-International Publishing House, Ltd., UK. This is an open access article under the CC BYNC-ND license (http://creativecommons.org/licenses/by-nc-nd/4.0/). Peer-review under responsibility of AMER (Association of Malaysian Environment-Behaviour Researchers), ABRA (Association of Behavioural Researchers on Asians) and cE-Bs (Centre for Environment-Behaviour Studies), Faculty of Architecture, Planning \& Surveying, Universiti Teknologi MARA, Malaysia.

DOI: https://doi.org/10.21834/ebpj.v5i15.2421. 
measures should be integrated into the business operation (Jasni, Yusoff, Zain, Md Yusoff, \& Shaffee, 2019). This is also considering risk minimisation and operational efficiency, as the impacts were factored into daily operations and compliance. Meanwhile, weak corporate environmental operationalisation will lead to low impact outcomes and vice versa. Although, in operationalisation, the corporate environmental practice was usually challenging and were often combined with different kinds of environmental activities (Nollet, Filis, \& Mitrokostas, 2016). In seeking the solution for corporate complexities, McKinsey Global Survey in 2018 provides evidence that companies should embrace digital technologies, methodologies, and management approaches.

The current corporate environmental practice in terms of reporting attempts to inform users, but unfortunately lacks engaging in operationalisation, and many companies do it only for the sake of reporting. Therefore, this study aims to refine resilient and sustainable business strategies, specifically the corporate environmental practice that focuses on the company's resources. The objectives of this study are 1) to understand the corporate environmental practice, and 2) to determine the key factors of successful corporate environmental practice from experienced Malaysia PLCs. This study attempts to answer "what are the key factors of successful corporate environmental practice?" It is interesting as this study attempts to fill the gaps of corporate behaviour in building a resilient business in Malaysia context.

\subsection{Literature Review}

In this study, corporate environmental practice optimises tangible and intangible resources of the company to implement business strategy and assess performance (Ray, Barney, \& Muhanna, 2004). Aragón-Correa and Sharma (2003) proposed that companies need to generate proactive strategies as companies' resources are drivers of a business. In managing environmental issues, the board of directors plays a crucial role in obtaining the resources for the company, making decisions regarding socially responsible investments and actions. The investment includes special equipment for company sustainability, relating to safety and control; non-complying with specific settings and Property Plant Equipment (PPE) guidelines may potentially revoke the environmental accreditation (Brooks \& Oikonomou, 2018). Despite typically associated with higher additional costs, being innovative and proactive in environmental management has helped companies to achieve economic growth and environmental sustainability concurrently. Many studies argue that small- and medium-sized companies' disadvantage is the lack of financial support compared to larger companies, which have extra monetary resources or high liquidity (Lee \& Rhee, 2007). Consequently, not all companies will equally benefit from the environmental strategy, as it depends on their financial capital resources abilities. However, Chung and Cho (2018) pointed out that regardless of the companies' size, a successful strategy is not about financial resources alone.

The existing literature on data governance is extensive. It focuses on resources used, which are measurable and traceable through specific ESG metrics that will be reflected in a reliable money measurement (Klassen \& Vachon, 2011). It has been seen that with data governance growth, the market tends to push the company's internal assessment to be transparent and traceable of the origin of the resources used in the product/service. To date, professional accounting bodies (International Federation of Accountants, 2020) reported rendering ESG to be traceable through various parameters leading to reliable decision-making to evaluate a company, contributing to the company's transparency and improvement in stakeholders' relations. Thus, tracing and optimising specific resource cycles allow decision-makers to identify consumption, emission, and waste hotspots (measurable) in their supply chains leading to a lower total temporal shortage. With regards to environmental, the progress in system integration, Environmental Management Accounting (EMA) system allow the monitoring of essential environmental metrics (carbon footprint, waste disposal) in supply chain management (Klassen \& Vachon, 2011), developing better methodologies, identifying key parameters and developing transparent reporting system for customers and other stakeholders (Li, Gong, Zhang, \& Koh, 2018). EMA is beyond conventional management accounting system, as previously, environmental information was identified as an overhead cost or hidden cost (Ghanem \& Sulaiman, 2016). Initially, it was hard to implement EMA. However, it is noted that the process and outcome can assist companies in measuring their business environmental impacts and allocating related costs and earnings/savings gained from environmental activities. This function is enhanced because collecting relevant data is the basis of the management's decision-making. Concisely, the literature emphasised that the accounting system is vital in technology resources.

At the core, data governance considered the integration of financial and non-financial data of the functional department within the company's values, goals, and daily routines and operations (Grewatsch \& Kleindienst, 2017) that support decision-making. Although, there are companies that are unaware of the advantages of data governance (financial and non-financial) in terms of environmental development impact (Darus, Yusof, \& Janggu, 2015; Klomp \& Clear, 2018). Therefore, numerous studies suggested companies learn to understand how changes in work processes ease the accomplishment of ESG goals (Langwell \& Heaton, 2016); with refined measurement comes a better practice. Table 1 is a summary of key factors for corporate environmental discussed in past studies.

Table 1. Key factors for corporate environmental from past studies

\begin{tabular}{lll}
\hline Key elements & & Past Studies \\
\hline Guidelines & Compliance & Brooks \& Oikonomou (2018) \\
Data governance & Measurable & Klassen \& Vachon (2011); Li, Gong, Zhang, \& Koh (2018) \\
& Traceable & International Federation of Accountants (2020) \\
& System Integration & Klassen \& Vachon (2011); Ghanem \& Sulaiman (2016) \\
& Monitoring & Klassen \& Vachon (2011); Li, Gong, Zhang, \& Koh (2018) \\
\hline
\end{tabular}




\subsection{Research Methodology}

In this study, we conducted a semi-structured interview with five Malaysian Public Listed companies, which are the pioneers of corporate environmental practices with more than seven years of experience being listed in Bloomberg's ESG Index. The appropriate participants were chosen via opportunistic sampling to address the research questions. This study believes that these companies are in the maturity stage of corporate environmental evolution. A semi-structured interview was used as a research technique since this research was guided by a deductive qualitative technique, which is a common technique used in collecting qualitative data (Lee \& Humphrey, 2006). It aids in understanding the complexity of a situation and participants' views concerning the meaning and context. For the interview, the data were in audio format; thus, data gathered were transcribed to text for qualitative analysis. The participants consist of Executive and Head of the Sustainability Department. The interviews were conducted in a span of 6 months (September 2018 - February 2019). Each interview took approximately 20-30 minutes and was conducted on a one-to-one basis. This study applies the sector risk classification (high/medium) from S\&P Global Ratings (2019). The overview of interviewed participants is tabled in Table 2.

Table 2. Overview of interviewed participants

\begin{tabular}{llll}
\hline Participants & Sector Risk & Sectors & Duration of the interview \\
\hline Alpha & Medium Risk & Homebuilders and developers & 30 minutes \\
Beta & Medium Risk & Telecommunication & 20 minutes \\
Gamma & Medium Risk & Telecommunication & 25 minutes \\
Delta & High Risk & Power generation (coal) & 20 minutes \\
Epsilon & High Risk & Agribusiness and commodity business & 30 minutes \\
\hline
\end{tabular}

This study had prepared initial interview questions, but with an 'active follow-up strategy', questions were continuously improvised and invented during the interviews. The formulation of the interview questions to answer the research questions of this study are summarised in Table 3. There are many qualitative analysis methods; however, thematic analysis was chosen to analyse this study's findings. The reliability of qualitative research highly depends on the researcher's insight, awareness, suspicions, and questions (Neuman, 2007), besides what the respondents tell the researcher. Meanwhile, part of the reliability element is the credibility of the respondents and their statements. Consequently, based on the context of this study, the implications through a generalisation of the larger population were predicted. Meanwhile, external validity was achieved through the number of companies interviewed; the similarities of the companies' situations were analysed, which assisted in understanding the context thoroughly.

Table 3. Interview question (IQ) formulation to answer the research question $(R Q$

\begin{tabular}{ll}
\hline How the RQ was addressed & $\mathrm{RQ}$ \\
\hline $\begin{array}{l}\text { What are the crucial elements to be considered in } \\
\text { corporate environmental practice? }\end{array}$ & $\begin{array}{l}\text { What are the key factors of successful corporate } \\
\text { environmental practice? }\end{array}$ \\
\hline
\end{tabular}

\subsection{Findings and Discussion}

\subsection{Coding category 1: Guidelines}

This study investigates further the key elements in measuring corporate environmental practice, which reveals a certain process to obtain accredited third-party compliance. Clear guidelines are vital for employees and certain settings, such as safety, health and control that involved Property Plant Equipment (PPE), which may potentially revoke the accreditation if not complied.

Interviewees from a high-risk sector said:

"We follow the Intergovernmental Panel on Climate Change (IPCC) guidelines on things that we should be measuring." (Delta)

"We have 16 company's policies that covered gender, carbon, and environment... It is quite difficult and challenging to control. So sometimes it could be costly" (Epsilon)

High-risk sector confirmed that they invest in knowledge and equipment to meet accredited third-party compliance, which supported Brooks and Oikonomou (2018). However, there are issues in handling compliance and maintaining the requirements due to the high cost.

\subsection{Coding category 2: Data Governance Measurable}

In the environmental measurement, most companies confirmed that medium-risk sector attempted to measure energy consumption, water consumption, and carbon emission.

These quotes from medium-risk sector justify this explanation:

"We measure the energy consumption, and water consumption" (Alpha) 
"For electricity and carbon measured through Tenaga bills, mileage claims... All those that cover electricity, scope one, and scope two" (Beta)

"Carbon figures... are those that are easy to measure" (Gamma)

On the other hand, one of the interviewees from the high-risk sector, Delta, disclosed that companies need to meet green efficiency targets for input-output ratio. Input-output techniques in supply chain resources are valuable for production optimisation and decisionmaking. This quote justify this explanation:

"Renewable energy, for instance, is expensive, but you're saving on the resources. Efficiency measure from outputinput ratio. So, just imagine if you add 100, you get an output of 60 , right? That's high for managing a business" (Delta)

The medium-risk sector stated that they attempted to quantify energy use, water consumption, and carbon emissions in environmental assessments. Meanwhile, one of the high-risk sector interviewees, Delta, revealed that businesses need to meet input-output ratio green efficiency goals and expand the performance indicator coverage as business growth. The statements are similar to studies by Klassen and Vachon (2011), and Li, Gong, Zhang, and Koh (2018).

\section{Traceable}

Next, in green product production, one of the interviewees from the high-risk sector, Epsilon, highlighted the importance of the source of the material to be traceable and transparent to increase consumers' confidence. This result reflects those of the International Federation of Accountants (2020), which also found that measurable environmental practices through metrics should reflect the actual number of resources used in generating income. The interviewee confirmed:

"The source should be traceable because customers want to know the origin of the sources... market demand that driven us to engage in the sustainability practice." (Epsilon)

The internal assessment agreed to be transparent and its origin to be traceable. It is noted that the assessment of policies compliance was mainly through ticking either 'yes' or 'no' in the box. Although internally, the company considers the practice as beyond scoring.

\section{System Integration}

The evolution of measurement is towards meaningful reporting that consists of measurable and reasonable support systems for improved continuous evaluation.

"The focus is indeed on sustainability management for governance; but we have a lot of different units that will do the handling, such as a handling safety unit, a handling certification unit, another one is handling environment unit, and a unit that handles the Lean Six Sigma." (Epsilon)

As mentioned by the interviewee from the medium-risk sector, Beta said:

"So, we have the FR (Financial Reporting) system; another is the NFR (Non-Financial Reporting) system. Also a system to capture supply chain..." (Beta)

Companies of both sectors agreed that gathering information is crucial for the financial and non-financial system-to support reports, monitor supply chain, and provide a comprehensive analysis for better integration of information and analysis, leading to meaningful decision-making. Good system integration is supported by previous studies (Darus, Yusof, \& Janggu, 2015; Klomp \& Clear, 2018) as well as enhanced supply chain management (Klassen \& Vachon, 2011).

\section{Monitoring}

Interestingly, in monitoring, companies have shown consistent improvement in refined measurement. As mentioned by the interviewees from the medium-risk sector:

"We used to have certain items that we would report again as part of our sustainability statement, but right now, we are implementing more accurate measures for sustainability reporting. And as I told you, it is still in progress because now we are in the transition phase, so we are moving towards becoming more aware of how to disclose. Our team and department right now are being engaged with. Somehow, we inform them what kind of information you should be submitting. They are kind of new in the gathering of information." (Alpha)

"The content of the report has evolved. It has been evolved from just reporting and listing activities. Recently, or the last three years or two years, our report is more organised, more comprehensive, and I can say that it is a bit more meaningful. It is better" (Gamma)

Meanwhile, internal audits are conducted by external auditors for a check and balance of the corporate environmental progress, and extensive performance indicators as business growth are important for the high-risk sector. As explained by an interviewee from the high-risk sector:

"If we have an internal audit, they will be audited by an external auditor. Thus, we will know where our level is, and we can analyse it. We can perform gap analysis for our sustainability" (Epsilon) 
In the meantime, there is consistent growth in the refined calculation of monitoring and auditing carried out by external auditors for a check and balance purpose of the progress and business growth. This is consistent with previous studies by Klassen and Vachon (2011) and Li, Gong, Zhang, and Koh (2018).

\section{Data Analysis}

A timely study is needed to check whether the performance is heading in the right direction. Interviewee reveals so under the mediumrisk sector remarks:

"So now, we do a gap analysis, and that is what we are working on. Honestly, currently, we have a discussion, progress update for our sustainability effort, engagement session, and our training...we understand and recognise how we are performing. Because of that, it is still work in progress" (Alpha)

Beta added:

"A lean analysis is to measure cost efficiency for continuous improvement. "Our network is extremely lean and efficient now. And there is a lot more we can do actually" (Beta)

Interviewees from the high-risk sector also confirmed in the following quote:

"The focus is indeed on sustainability management for governance; there is a unit handling lean six sigma that works for continuous improvement." (Epsilon)

"We have performance indicator... for many years already. So, as we grow the business, we expand the coverage as well." (Delta)

The assertions suggest data analysis as the distinction between expectation and reality. Areas that are lacking are expected to improve further. Two types data analysis; financial accounting (e.g. gap analysis and performance indicator) and contemporary management accounting (e.g. lean six sigma analysis) are among techniques used by the companies as a continuous improvement for better corporate environmental practice.

Overall, Epsilon from high-risk sector scores the highest, followed by three companies from the medium-risk sector (Alpha and Beta) and Delta (high-risk sector). Meanwhile, the lowest scores is Gamma (medium-risk sector). Among all, Epsilon, an agribusiness and commodity company received greater external pressures than other sector pressure, namely backlashed and boycotted by local and international activists of Non-Government Organisations (NGO). Thus, it is no surprise that Epsilon is heading towards good corporate environmental practice, as the best way to mitigate their business risks. Table 4 presents the qualitative results on key factors of successful corporate environmental practice.

Table 4. Qualitative results on key factors of successful corporate environmental practice

\begin{tabular}{llccccc}
\hline & \multicolumn{3}{c}{ Medium -risk sector } & \multicolumn{2}{c}{ High-risk sector } \\
\hline Guidelines & Alpha & Beta & Gamma & Delta & Epsilon \\
Data governance & $\begin{array}{l}\text { Measurable } \\
\text { Traceable }\end{array}$ & 1 & 1 & 1 & 1 & 1 \\
& $\begin{array}{l}\text { System Integration } \\
\text { Monitoring }\end{array}$ & 1 & 1 & & & 1 \\
& *Data Analysis & 1 & 1 & 1 & & 1 \\
\hline & Total score & 3 & 3 & 2 & 3 & 5 \\
\hline
\end{tabular}

Importantly, this study validated previous findings that guidelines and data governance are the two critical and compelling aspects that ensure successful corporate environmental practice. The corporate environmental practice is focusing on meaningful reporting, and the increasing coverage of performance evaluation show the growth of the business operation. Data gathering and synchronising are working towards a more integrated picture of corporate environmental practice. The study's results draw attention to the importance of considering data analysis (financial accounting and management accounting) in data governance, which contributed to the continuous improvement of corporate environmental practice. The commitment to improve the implementation of corporate environmental practice is not only focusing on the financial, which is supported by other non-financial that help the company to perform reliable decision-making process. On top of that, from the core perspective, corporate environmental practice integration should be within the vision, mission, daily routines, and business operations.

\subsection{Conclusion}

In this study, the researchers attempt to understand the corporate environmental practice and to determine its key factors from experienced Malaysia PLCS of a successful corporate environmental practice. The study identified that clear environmental guidelines and strong data governance contributed to the success of corporate environmental practice. These results add to the rapidly expanding field of support systems in the internal measurement of corporate environmental practice. This study shows that both the high-risk sector and medium-risk sector are working progressively in improving their data governance for business growth and preparation towards IR 
4.0. For future research, this study suggests the inclusion of more participants from other sectors; low-risk sector and small-medium enterprise, which would offer a better representation of corporate behaviour in Malaysia. Interestingly, this study has provided a novel perspective, which best represents good corporate citizenship towards sustainability-centred work culture.

\section{Acknowledgements}

The authors would like to express sincere gratitude to the Faculty of Accountancy, Puncak Alam Campus, Universiti Teknologi MARA (UiTM), Malaysia, for funding this research project.

\section{Paper Contribution to Related Field of Study}

This study provides further insight into greater corporate environmental practice to build a resilient business in the context of Malaysia.

\section{References}

Aagaard, A. (2018). Managing Sustainable Innovation (pp. 13-28). Springer, Cham. https://doi.org/10.1007/978-3-319-93629-1_2

Aluchna, M., \& Idowu, S. O. (2017). Responsible Corporate Governance: Towards Sustainable and Effective Governance Structures. CSR, Sustainability, Ethics \& Governance. https://doi.org/10.1007/978-3-319-55206-4

Aragón-Correa, J. A., \& Sharma, S. (2003). A contingent resource-based view of proactive corporate environmental strategy. Academy of Management Review, 28(1), 71-88. https://doi.org/10.5465/AMR.2003.8925233

Brooks, C., \& Oikonomou, I. (2018). Editorial: The effects of environmental, social and governance disclosures and performance on firm value: A review of the literature in accounting and finance. The British Accounting Review, 50(1), 1-15. https://doi.org/10.1016/J.BAR.2017.11.005

Chung, J., \& Cho, C. H. (2018). Current Trends within Social and Environmental Accounting Research: A Literature Review. Accounting Perspectives, 17(2), $207-239$. https://doi.org/10.1111/1911-3838.12171

Darus, F., Yusof, W. M., \& Janggu, T. (2015). Environmental Protection and Value Creation. In 6thAsia-Pacific International Conference on Environment-Behaviour Studies, Barcelona School of Architecture (ETSAB), Barcelona, Spain, 31 Aug. - 05 Sep. 2015. Retrieved from https://ebpj.eiph.co.uk/index.php/EBProceedings/article/view/219/138

Ghanem, N. B., \& Sulaiman, S. (2016). Management Accounting System, Information Quality and Organizational Performance: Evidence From Libya. Asia-Pacific Management Accounting Journal, 11(2). Retrieved from http://ir.uitm.edu.my/id/eprint/29957/1/29957.pdf

Grewatsch, S., \& Kleindienst, I. (2017). When Does It Pay to be Good? Moderators and Mediators in the Corporate Sustainability-Corporate Financial Performance Relationship: A Critical Review. Journal of Business Ethics, 145, 383-416. https://doi.org/10.1007/s10551-015-2852-5

International Federation of Accountants. (2020). Sustainable Development Goals Disclosure (SDGD) Recommendations. Retrieved from https://www.ifac.org/knowledgegateway/contributing-global-economy/publications/sustainable-development-goals-disclosure-sdgd-recommendations

Jasni, N. S., Yusoff, H., Zain, M. M., Md Yusoff, N., \& Shaffee, N. S. (2019). Business strategy for environmental social governance practices: evidence from telecommunication companies in Malaysia. Social Responsibility Journal. https://doi.org/10.1108/SRJ-03-2017-0047

Klassen, R. D., \& Vachon, S. (2011). Greener Supply Chain Management. Oxford University Press. https://doi.org/10.1093/oxfordhb/9780199584451.003.0015

Klomp, S., \& Clear, A. (2018). Senior Management Perceptions of CSR Impact: Long-term Investment for Social Good or Necessary Cost? (pp. 177-191). Springer, Cham. https://doi.org/10.1007/978-3-319-71449-3_11

Langwell, C., \& Heaton, D. (2016). Using human resource activities to implement sustainability in SMEs. Journal of Small Business and Enterprise Development, 23(3), 652-670. https://doi.org/10.1108/JSBED-07-2015-0096

Lee, B., \& Humphrey, C. (2006). More than a numbers game: qualitative research in accounting. Management Decision, 44(2), $180-197$. https://doi.org/10.1108/00251740610650184

Lee, S. Y., \& Rhee, S. K. (2007). The change in corporate environmental strategies: A longitudinal empirical study. Management Decision, 45(2), $196-216$. https://doi.org/10.1108/00251740710727241

Li, Y., Gong, M., Zhang, X.-Y., \& Koh, L. (2018). The impact of environmental, social, and governance disclosure on firm value: The role of CEO power. The British Accounting Review, 50(1), 60-75. https://doi.org/10.1016/J.BAR.2017.09.007

Mohd Zawawi, N. F., \& Abd Wahab, S. (2019). Organizational sustainability: a redefinition? Journal of Strategy and Management, 12(3), 397-408. https://doi.org/10.1108/JSMA-08-2018-0077

McKinsey. (2018). The CFO's role: Prioritise, transform, repeat. Retrieved July 26, 2020, from https://www.mckinsey.com/business-functions/strategy-and-corporatefinance/our-insights/the-new-cfo-mandate-prioritize-transform-repeat

Neuman, W. L. (2007). Basics of Social Research: Qualitative and Quantitative Approaches (2nd ed.). Boston: Pearson. 
Nollet, J., Filis, G., \& Mitrokostas, E. (2016). Corporate social responsibility and financial performance: A non-linear and disaggregated approach. Economic Modelling, 52, 400-407. https://doi.org/10.1016/j.econmod.2015.09.019

Ray, G., Barney, J. B., \& Muhanna, W. A. (2004). Capabilities, business processes, and competitive advantage: choosing the dependent variable in empirical tests of the resource-based view. Strategic Management Journal, 25(1), 23-37. https://doi.org/10.1002/smj.366

S\&P Global Ratings. (2019). The ESG Risk Atlas: Sector And Regional Rationales And Scores What Is The ESG Risk Atlas? What Can It Do? The ESG Risk Atlas: Sector and Regional Rationales And Scores. Retrieved from www.spglobal.com/ratingsdirect 